\title{
Turkish Women's Experiences and Expectations of Vaginal Examinations in Labour: A Qualitative Study
}

\author{
Gamze Tezkereci, Arzu Akpinar, Hatice Balci Yangin \\ Akdeniz University, Nursing Faculty
}

\begin{abstract}
Problem statement: Vaginal examination plays an important role during labour. The vaginal examination give the provider the necessary information about cervical dilatation, effacement, fetal head position and status of membranes in labour. But it's an uncomfortable experience and during labour, women may report feelings of fear, shame, pain and loneliness.
\end{abstract}

Objective: The aim of the study was to explore women's experiences and expectations during vaginal examinations in labour.

Methods: This qualitative research design based upon qualitative with phenomenological approach. A purposive sample of 13 women post-delivery who had given birth vaginally and were able to speak and read Turkish. Data were collected by tape-recorded open-ended interviews during the early postnatal period in a maternity clinic of a state hospital in Antalya, Turkey. The interviews were started by asking "Please tell me your experience during vaginal examination". Probing questions were also used such as "Can you tell me what you thought about vajinal examination?", "Can you explain expectation from health professionals during vaginal examination". Data analysis were phenomenological hermeneutic analysis based upon Riceour's interpretation theory. Ethical approval was obtained from Ethical Committee of Antalya Training and Research Hospital. Also permission was obtained for the voice recordings of the interviews from women at the beginning of the interviews. The names of the participants were kept confidential.

Results: Data were classified into four themes that "emotional", "thoughts", "experiences" and "expectations from health professionals and others". Experiences divided into two subthemes as experiences that complicing and facilitating the vaginal examination. The women accepted necessity the vaginal examinations for their own and their baby's health during labour.
But some women stated that vaginal examination was unnecessary during pregnancy. Pain, embarrassment, fear and excitement were frequently experienced during vaginal examination. Some women felt embarrassed when examined by a male doctor, but the attitude, approach and skill of the examiner was generally found to be more important than gender. The women were wanted a doctor who is an expert or experienced, kind, clean, friendly, informative, relaxing. The women wanted to be supported during the examination by nurses and midwifery. Almost all women were expected a nurse or midwifery who has a humanistic perspective such as smilingly, warm, gentle, empathic, non-judgmental, motivator. Conclusions: Vaginal examination should be discussed with women. The health professionals should be sensitive towards the needs of women in labour, including the provision of explanations and information regarding vaginal examinations.

Keywords: vaginal examination, labour, experiences, expectations.

\begin{tabular}{cccccc}
\hline Participant & Age & Education & $\begin{array}{c}\text { Marriage } \\
\text { Duration } \\
\text { (year) }\end{array}$ & Gravida & Para \\
\hline P1 & 39 & None & 23 & 7 & 5 \\
P2 & 37 & None & 8 & 5 & 4 \\
P3 & 18 & Primary S. & 2 & 1 & 1 \\
P4 & 23 & High S. & 1 & 1 & 1 \\
P5 & 27 & High S. & 5 & 1 & 1 \\
P6 & 20 & Secondary S. & 3 & 2 & 2 \\
P7 & 22 & Secondary S. & 1 & 1 & 1 \\
P8 & 19 & Secondary S. & 1 & 1 & 1 \\
P9 & 30 & High S. & 12 & 2 & 2 \\
P10 & 17 & None & 1 & 1 & 1 \\
P11 & 25 & Secondary S. & 5 & 2 & 2 \\
\hline P12 & 29 & Secondary S. & 10 & 3 & 3 \\
\hline P13 & 23 & Secondary S. & 1 & 1 & 1 \\
\hline
\end{tabular}

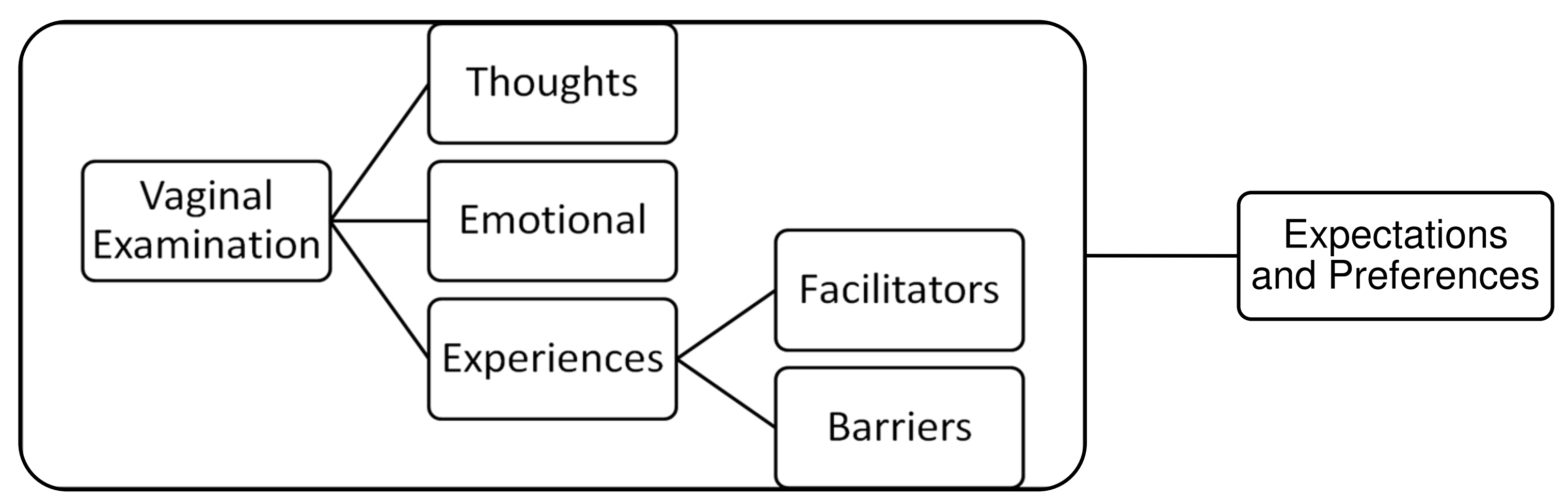

